\title{
STANDAR OPERASIONAL PROSEDUR BIDANG "K3" PADA UNIT SARANA PT. KERETA API INDONESIA (PERSERO) DAERAH OPERASI 6 YOGYAKARTA
}

\author{
Widodo Hariyono \\ Jurusan Ilmu Kesehatan Masyarakat, Pusat Studi Keselamatan dan Kesehatan Kerja, \\ Fakultas Kesehatan Masyarakat, Universitas Ahmad Dahlan (UAD), Yogyakarta \\ E-mail: widodohariyono@yahoo.com
}

\begin{abstract}
One of the important programs of PT Kereta Api (Persero) in creating a quality product, both locomotives and railway carriages was to realize standard working system. Facility unit of Regional Operations (Daop) 6 Yogyakarta, had a very important role in determining the feasibility and readiness of locomotives and carriages before leaving, which indirectly determined the safety and comfort of passengers. Care of locomotives and carriages on a regular basis to maintain locomotives and carriages were always in optimal condition. Each worker of Unit Facility should understand and implement the SOP OHS that had been determined. SOP OHS could provide information to workers in order to carry out their duties and responsibilities with the safe and sound, so accidents and occupational diseases could be avoided, as well as to achieve the goals set by PT Kereta Api (Persero). Objective: This study aimed to determine the application of SOP OHS in Facility Unit of PT Kereta Api Indonesia (Persero) Daop 6 Yogyakarta. Methods : The method used in this study was descriptive qualitative. The subjects of this study included junior managers, supervisors, and workers carriage depot Yogyakarta, junior managers, supervisors, and workers locomotive depot Yogyakarta. Data were collected through interviews and direct observation. The data were analyzed descriptively by using triangulation of sources and methods. Results : The results showed that the policy of SOP OHS in the facility Unit of PT Kereta Api Indonesia (Persero) was created by team of Safety, Health, and Environment (SHE) which has been reviewed and adjusted to Occupational Health and Safety Management System and ISO 9001: 2008. The SOP OHS Policy in the Facility Unit included (1) Personal Protective Equipment (PPE), (2) the reporting and investigation of incidents, accidents and occupational diseases, (3) inspection of work, (4) signs of K3, (5) maintenance (6) emergencies. Worker's understanding on the facility unit in the SOP OHS was good, but the worker's adherence to SOP OHS should be improved. Conclusions: Application of SOP OHS in the facility unit of PT Kereta Api Indonesia (Persero) Daop 6 Yogyakarta has met the requirements, but there were some things that must be addressed and completed.
\end{abstract}

Keywords : SOP, K3, Railways.

\section{PENDAHULUAN}

Prosedur kerja yang sistematis dalam pelaksanaan tugas di tempat kerja merupakan faktor yang terpenting dalam sistem manajemen keselamatan dan kesehatan kerja secara menyeluruh. Suatu pekerjaan membutuhkan adanya suatu petunjuk sebagai pegangan bagi petugas untuk mengurangi resiko terjadinya kecelakaan. Setiap pekerja perlu mengikuti prosedur kerja yang ditetapkan. Hal ini penting untuk menjamin keselamatan dan kesehatan pekerja tersebut. Prosedur tersebut biasanya dituangkan dalam bentuk Standar Operasional Prosedur (SOP) (Suci, R. dkk).

Standar Operasional Prosedur (SOP) dapat memberikan kemudahan kepada setiap pekerja dalam melaksanakan tugasnya sehingga dapat memberikan hasil pekerjaan yang bermutu dan berkualitas, disamping terhindar dari risiko terpajan atau tertular penyakit. Pemahaman, sikap serta kesadaran adalah hal yang penting, yang harus dimiliki oleh setiap pekerja dalam menerapkan dan mematuhi SOP tersebut sehingga setiap pekerja melakukan pekerjaannya dengan baik dan benar. 
PT Kereta Api Indonesia (Persero) merupakan salah satu Badan Usaha Milik Negara (BUMN) yang diberi tugas dan tanggung jawab untuk menyelenggarakan jasa angkutan kereta api. PT Kereta Api Indonesia (Persero) selalu mengutamakan kualitas, kepuasan dan keselamatan penumpang. Unit sarana yang terdiri dari dipo kereta dan lokomotif memiliki peran yang sangat penting dalam menentukan kelayakan dan kesiapan lokomotif dan kereta sebelum berangkat yang secara tidak langsung menentukan keselamatan orang banyak sebagai penumpang. Perawatan terhadap lokomotif dan kereta secara berkala menjaga lokomotif dan kereta selalu dalam keadaan optimal. Setiap pekerja unit sarana wajib memahami dan melaksanakan SOP K3 yang sudah ditentukan Setiap kegiatan di unit sarana baik di dipo lokomotif maupun dipo kereta Yogyakarta telah diatur oleh SOP yang wajib dipahami dan dilaksanakan oleh setiap pekerja. SOP K3 di unit sarana dibuat oleh team Safety, Health \& Environment (SHE). Keberhasilan pelaksanaan SOP K3 di perusahaan tidak lepas dari sikap kepatuhan personal baik dari pihak karyawan maupun pihak manajerial dalam melaksanakan peraturan kebijakan K3. Penerapan SOP K3 di unit sarana sangat penting tapi sulit untuk diterapkan secara merata (PT Kereta Api Indonesia, 2014).

Setiap proses pekerjaan di unit sarana banyak menggunakan bahan-bahan yang dapat menimbulkan potensi bahaya kerja. Dibandingkan unit lain yang ada di PT Kereta Api Indonesia (Persero) Daerah Operasi VI Yogyakarta, unit sarana memiliki risiko terjadinya kecelakaan paling tinggi. Jika para karyawan tidak melaksanakan proses pekerjaan sesuai dengan SOP K3 yang telah ditetapkan dengan baik maka akan timbul potensi bahaya kerja yang dapat membahayakan pekerja itu sendiri.
Standar Operasional Prosedur (SOP) Keselamatan dan Kesehatan Kerja (K3) memiliki peranan yang sangat penting dalam sebuah perusahan. SOP K3 dapat menjamin hak dari setiap karyawan. Kerugian yang disebabkan oleh kecelakaan sangatlah besar sehingga semua pihak yang terlibat baik pekerja, pimpinan perusahan dan penentu kebijakan harus memahami dan menerapkan program-program tentang $\mathrm{K} 3$ sehingga tercipta lingkungan kerja yang aman, nyaman dan sehat. Maka dengan demikian jumlah kecelakaan kerja dapat ditekan dan perusahan tidak akan mengalami suatu kerugian.

Berdasarkan hasil observasi awal yang dilakukan pada bulan Februari 2016 di Unit Sarana PT Kereta Api Indonesia (Persero) Daerah Operasi VI Yogyakarta diperoleh hasil berupa (1) PT Kereta Api Indonesia (Persero) memiliki Sistem Manajemen Keselamatan dan Kesehatan Kerja (SMK3) ISO 9001 : 2008 (2). PT Kereta Api Indonesia (Persero) memiliki tim Safety Health and Environment (SHE) secara terpusat, (3). Terdapat SOP K3 yang mengatur setiap kegiatan yang ada di unit sarana. Hasil wawancara pada assistan manager unit sarana menyebutkan bahwa SOP K3 sangat penting untuk selalu dipatuhi dan dilaksanakan setiap pekerja PT Kereta Api Indonesia (Persero). Assistan manager unit sarana juga menambahkan bahwa setiap pekerja harus dan wajib memahami serta melaksanakan SOP K3 yang sudah ditetapkan.

Masalah yang ada di Unit Sarana PT Kereta Api Indonesia (Persero) Daerah Operasi VI Yogyakarta yaitu (1). Kurangnya penyediaan alat pelindung diri, (2). Pengadaan alat pelindung diri telat, (3). Terdapat karyawan yang tidak menggunakan alat pelindung diri pada saat berada di tempat kerja dan (4). Tidak semua kecelakaan dan penyakit akibat kerja dilaporkan dan dicatat. Berdasarkan uraian tersebut peneliti tertarik menganalisis penerapan SOP K3 di Unit Sarana PT Kereta Api Indonesia Daerah Operasi VI Yogyakarta. 


\section{METODE PENELITIAN}

Jenis penelitian ini adalah deskriptif kualitatif. Penelitian deskriptif adalah jenis penelitian yang memberikan gambaran atau uraian atas suatu keadaan sejelas mungkin tanpa ada perlakuan terhadap obyek yang diteliti ${ }^{3}$. Penelitian ini dilaksanakan di unit sarana PT Kereta Api Indonesia (Persero) Daerah Operasi VI Yogyakarta, tepatnya pada unit kerja di Stasiun Tugu yaitu di dipo kereta Yogyakarta dan dipo lokomotif Yogyakarta. Waktu penelitian dilaksanakan pada bulan Maret 2016. Subyek dalam penelitian ini adalah Junior Manager dipo kereta dan dipo lokomotif Yogyakarta, supervisor dipo kereta dan dipo lokomotif Yogyakarta dan pekerja dipo kereta dan dipo lokomotif Yogyakarta.

\section{HASIL DAN PEMBAHASAN}

\subsection{Hasil Penelitian}

1) Deskripsi Subyek Penelitian

Jumlah subyek dalam penelitian ini sebanyak 10 orang yang dianggap dapat memberikan informasi yang lengkap dan akurat. Subyek tersebut terdiri dari 2 junior manager, 2 supervisor dan 6 pekerja di dipo lokomotif dan dipo kereta Yogyakarta. Junior manager dipilih karena junior manager yang lebih mengerti tentang SOP K3, supervisor dipilih karena supervisor yang mengawasi SOP K3 dan pekerja adalah orang yang menjalankan dan menggunakan SOP K3.
2) Penerapan SOP K3 di Unit Sarana PT Kereta Api Indonesia (Persero) Daerah Operasi VI Yogyakarta.

Setelah melakukan observasi dan wawancara pada junior manager, supervisor dan pekerja dipo lokomotif dan dipo kereta Yogyakarta, maka hasil dikelompokkan berdasarkan variabel yang diteliti dalam penelitian ini, diantaranya adalah sebagai berikut :

\section{a) Kebijakan SOP K3}

Kebijakan SOP K3 di unit sarana dibuat oleh team Safety, Health \& Environment (SHE) yang telah dikaji dan disesuaikan dengan SMK3 dan ISO 9001 : 2008 serta peraturan perkeretaapian nasional. Team SHE berada di kantor pusat PT Kereta Api Indonesia (Persero) yang terletak di Jl. Perintis Kemerdekaan No. 1 Bandung. Berikut adalah kutipan hasil wawancara dengan junior manager dipo lokomotif Yogyakarta.

"Ada mas, untuk kebijakan SOP K3 disini dibuat oleh SHE nya mas. SHE nya di kantor pusat sana, di Bandung" (Responden R1).

Kebijakan SOP K3 di unit sarana PT Kereta Api Indonesia (Persero) Daerah Operasi VI Yogyakarta sama dengan unit sarana di daerah operasi lainnya di Indonesia. Pernyataan ini diungkapkan oleh junior manager dipo kereta Yogyakarta.

\begin{tabular}{|cllc|}
\hline No. & Subyek Penelitian & Jumlah & Kode \\
\hline 1. & $\begin{array}{l}\text { Junior Manager dipo } \\
\text { 1okomotif Yogyakarta }\end{array}$ & 1 Orang & R1 \\
\hline 2. & $\begin{array}{l}\text { Junior Manager dipo } \\
\text { kereta Yogyakarta }\end{array}$ & 1 Orang & R2 \\
\hline 3. & $\begin{array}{l}\text { Supervisor dipo } \\
\text { lokomotif Yogyakarta }\end{array}$ & 1 Orang & R3 \\
\hline 4. & $\begin{array}{l}\text { Supervisor dipo } \\
\text { kereta Yogyakarta }\end{array}$ & 1 Orang & R4 \\
\hline 5. & $\begin{array}{l}\text { Pekerja dipo } \\
\text { lokomotif Yogyakarta }\end{array}$ & 3 Orang & R5, R6, R7 \\
\hline 6. & $\begin{array}{l}\text { Pekerja dipo kereta } \\
\text { Yogyakarta }\end{array}$ & 3 Orang & R8, R9, R10 \\
\hline
\end{tabular}

Gambar 1. Tabel Jumlah Junior Manager dan Pekerja Dipo Kereta Api di Yogyakarta. 
"Ada SOP K3 nya mas, untuk kebijakan SOP K3 nya dibuat oleh team SHE. Kebijakan SOP K3 di PT Kereta Api Indonesia dari daop satu sampai daop sembilan sama mas. Baik dipo lokomotif maupun dipo kereta sama saja, balai yasa juga sama kebijakan SOP K3 nya" (Responden R2).

Kebijakan SOP K3 di unit sarana terdiri dari 6 komponen utama yang terdiri dari: Alat Pelindung Diri (APD); Pelaporan dan Penyelidikan Insiden, Kecelakaan dan Penyakit Akibat Kerja; Inspeksi Kerja; Rambu-Rambu K3; Pemeliharaan dan Keadaan Darurat.

"Kebijakan SOP K3 nya yang utama ada 6 kalau nggak salah mas, seperti alat pelindung diri itu yang paling utama, kalau ada keadaan darurat, apar, pelaporan kecelakaan, hmmm.... ramburambu K3 mas, kayak itu mas" (Responden R3).

Pernyataan senada juga disampaikan oleh responden lainnya dalam kutipan wawancara berikut :

"Ada beberapa mas, SOP nya seperti APD mas, kalau masuk tempat kerja harus pakai helm, sepatu dan lain-lain, terus SOP kalau ada kecelakaan di tempat kerja, hmmm... kalau dalam keadaan darurat seperti kebakaran mas, cara pakai apar" (Responden R7).

\subsection{Pemahaman dan Kepatuhan Pekerja Unit Sarana Terhadap SOP K3}

Setiap kegiatan di unit sarana baik di dipo lokomotif maupun dipo kereta Yogyakarta telah diatur oleh SOP K3 yang wajib dipahami dan dilaksanakan oleh setiap pekerja. Hal ini disampaikan oleh junior manager dipo lokomotif dan dipo kereta Yogyakarta dalam kutipan wawancara sebagai berikut :
"Setiap pekerja harus dan wajib mas memahami dan mematuhi SOP K3 perusahaan, karena SOP K3 itu sangat penting...nggak hanya bagi perusahaan, tapi itu bagi pekerja sendiri juga mas..." (Responden R1).

“...sebelum bekerja kita apel dulu mas, brifing dulu sebelum bekerja, berdoa dan selalu memberikan instruksi kepada seluruh pekerja untuk selalu mentaati dan mematuhi peraturan yang ada termasuk SOP K3. Memang kita tekankan bagi para seluruh pekerja untuk selalu melaksanakan pekerjaannya sesuai dengan SOP K3. (Responden R2).

Tidak ada team khusus yang memantau kepatuhan pekerja unit sarana terhadap SOP K3. Setiap pekerja saling mengingatkan satu sama lain jika terdapat pekerja yang tidak mematuhi SOP K3. Serta tidak ada sanksi bagi pekerja yang melanggar SOP K3, sanksi hanya berupa teguran dari supervisor atau junior manager. Pernyataan ini diungkapkan oleh salah satu pekerja dipo kereta Yogyakarta dalam kutipan berikut :

"hmmm... kalau team khusus yang memantau kepatuhan pekerja terhadap SOP K3 sepertinya nggak ada mas. Karena kita bekerja sesuai kesadaran diri bahwa mematuhi SOP K3 itu penting seperti memakai APD saat bekerja. (Responden R8).

Pernyataan yang sama juga diungkapkan oleh salah satu pekerja dipo lokomotif Yogyakarta.

"tidak ada mas, paling cuma supervisor atau pak JM kalau misalnya mereka tau kita kerja nggak sesuai sama prosedur atau nggak pakai APD misalnya, ya ditegur mas", (Responden R6).

Kepatuhan pekerja unit sarana terhadap SOP K3 sangat penting agar setiap pekerja dapat melaksanakan tugas dan tanggung 
jawabnya dengan aman dan nyaman sehingga terhindar dari penyakit atau kecelakaan akibat kerja, serta agar tercapai tujuan yang telah ditetapkan oleh perusahaan.

"saya selalu mematuhi prosedur yang ada mas, sebelum bekerja apel dulu, selalu ditekankan untuk mematuhi prosedur maupun peraturan perusahaan. Untuk APD pun saya selalu memakainya mas, seperti masker, helm, sepatu. kalau istirahat aja dilepas" (Responden R10).

"oh selalu itu mas, pasti itu, wajib soalnya mematuhi SOP yang ada. Saya pribadi selalu pakai APD kalau bekerja, semua lengkap saya pakai, meskipun ada beberapa teman-teman yang terkadang nggak pakai mas. Ya namanya juga kesadaran masing-masing sih mas, kita cuma saling mengingatkan. Kalau ada pak JM ya ditegur mas, kalau berkali-kali ya mungkin kena sanksi" (Responden R9).

Salah satu aspek yang membentuk kepatuhan adalah pengetahuan dari pekerja terhadap suatu obyek / meteri. Pengetahuan dalam hal ini mengenai SOP K3 yang diterapkan oleh perusahaan. Berdasarkan hasil wawancara peneliti dengan para responden bahwa pemahaman pekerja unit sarana pada SOP K3 sudah sangat baik, akan tetapi kepatuhan pekerja unit sarana terhadap SOP K3 perlu ditingkatkan.

Pernyataan ini didukung oleh hasil pengamatan langsung yang dilakukan oleh peneliti bahwa masih ada beberapa pekerja yang tidak memakai APD seperti helm dan sarung tangan di tempat kerja, padahal di area tersebut sudah jelas terdapat ramburambu yang mewajibkan pekerja memakai APD.

Berdasarkan penjelasan di atas menunjukkan bahwa penggunaan alat pelindung diri yang merupakan kewajiban bagi setiap pekerja terutama di unit sarana belum digunakan secara baik dikarenakan kesadaran pekerja masing-masing belum cukup baik untuk digunakan pada waktu pekerjaan kecuali pada waktu - waktu tertentu saja atau dalam keadaan darurat saja.

\subsection{Kesesuaian SOP K3}

Kesesuaian SOP K3 yaitu kecocokan atau keselarasan antara penerapan SOP K3 di unit sarana dengan SOP K3 yang sudah ditetapkan oleh PT Kereta Api (Persero). Penerapan SOP K3 di unit sarana PT Kereta Api Indonesia (Persero) Daerah Operasi VI Yogyakarta sebagian besar telah sesuai dengan SOP K3 yang sudah ditetapkan oleh PT Kereta Api Indonesia (Persero), akan tetapi ada beberapa hal yang perlu dibenahi dan dilengkapi. Berikut ini adalah kutipan wawancara dengan junior manager dipo lokomotif Yogyakarta :

"kalau untuk sesuai tidak nya penerapan SOP K3 di sini dengan SOP K3 yang sudah ditetapkan sebagian besar sudah sesuai mas. Mungkin ada beberapa yang perlu dibenahi, seperti pengadaan APD yang telat, padahal itu kan penting, ini ada beberapa pegawai baru yang belum dapat APD. Kalau untuk SOP K3 seperti pengadaan APAR, rambu-rambu K3 sepertinya sudah sesuai mas" (Responden R1).

Pernyataan serupa juga disampaikan oleh junior manager dipo kereta Yogyakarta, berikut kutipan pernyataan tersebut :

"hampir semua sesuai sih mas sama SOP $K 3$ yang sudah ditetapkan, sudah ada APAR, rambu-rambu K3 juga ada, pemeliharaan alat selalu dilakukan, APD juga ada, setiap pekerja punya masingmasing APD meskipun pengadaannya telat mas, kan kita cuma mengajukan mas kalau APD, setelah kita ajukan APD ke atas baru diberi" (Responden R2).

Pernyataan hampir sama juga disampaikan oleh supervisor dipo lokomotif Yogyakarta.

"kalau untuk SOP K3 yang APAR, rambu-rambu K3, terus keadaan darurat 
sudah sesuai semua mas. Mungkin cuma APD mas yang saya rasa kurang. Terkadang pengadaannya telat, padahal kita sudah mengajukan ke atas, kan prosedurnya untuk APD kita yang mengajukan ke atas mas, minta APD apa, misalnya ada yang sudah rusak. Terus ada beberapa APD ini yang sudah waktunya ganti sebenernya, ini juga ada beberapa pegawai baru yang belum dapat APD mas. Padahal kan APD sangat penting mas" (Responden R3).

“...sudah cukup mas, sudah sesuai. Mungkin APD nya ya mas, terkadang telat datangnya. Harusnya udah ganti tapi belum dapat ganti. Beberapa temen pegawai baru juga belum dapat ini" (Responden R9).

“....sama kalau misalnya ada insiden atau kecelakaan kecil seperti tergores atau terjepit mereka tidak lapor, padahal kan semua insiden atau kecelakaan baik kecil atau fatal tetap harus dilaporkan dan dicatat" (Responden R4).

Hal ini menunjukkan bahwa SOP K3 APD serta pelaporan dan penyelidikan insiden, kecelakaan dan penyakit akibat kerja di unit sarana belum sesuai dengan SOP yang sudah ditentukan oleh unit sarana. Pernyataan tersebut didukung dengan tidak adanya dokumen atau catatan laporan insiden atau kecelakaan kecil seperti tergores, terjepit, terpecik api dan sebagainya yang ada di unit sarana. Hasil pengamatan di lapangan juga menunjukkan bahwa beberapa helm yang sudah rusak tetap dipakai dan beberapa pegawai baru yang belum mendapatkan APD.

\subsection{Pembahasan}

\subsubsection{Kebijakan SOP K3}

Kebijakan SOP K3 merupakan suatu standar atau prosedur yang dapat memberikan informasi kepada para pekerja agar dapat melaksanakan tugas dan tanggung jawabnya dengan aman dan nyaman sehingga terhindar dari penyakit atau kecelakaan akibat kerja, serta agar tercapai tujuan yang telah ditetapkan oleh perusahaan. Kebijakan SOP K3 di unit sarana dibuat oleh tim SHE yang berada di kantor pusat PT Kereta Api Indonesia (Persero) yang berada di J1. Perintis Kemerdekaan No. 1 Bandung. Kebijakan SOP K3 di unit sarana telah dikaji dan disesuaikan dengan SMK3 dan ISO 9001 : 2008 serta peraturan perkeretaapian nasional. Kebijakan SOP K3 di unit sarana di setiap daerah operasi sama.

Kebijakan SOP K3 di unit sarana dibagi menjadi 6 komponen utama yaitu Alat Pelindung Diri (APD); Inspeksi Kerja; Rambu - Rambu K3; Pelaporan dan Penyelidikan Insiden, Kecelakaan dan Penyakit Akibat Kerja; Pemeliharaan dan Keadaan Darurat. Hal ini sesuai dengan dokumen yang ditunjukkan oleh assistan manager unit sarana bahwa terdapat 6 SOP K3 utama.

Unit sarana mewajibkan setiap pekerja memakai APD saat memasuki tempat kerja sesuai dengan SOP K3 yang telah ditetapkan seperti helm, safety shoes, pakaian kerja, sarung tangan dan alat pelindug diri khusus seperti kacamata saat proses pengelasan dan ear muff atau ear plug saat melakukan maintenance atau pengecekan terhadap lokomotif atau kereta. Unit sarana juga memiliki rambu-rambu K3 seperti kewajiban memakai APD, rambu larangan, peringatan, informasi hingga jalur evakuasi. Ramburambu K3 di unit sarana juga sudah sesuai dengan SOP seperti penempatan, jumlah, bentuk, warna serta pemasangan. Salah satu upaya perusahaan agar pekerjanya sadar akan pentingnya $\mathrm{K} 3$ dengan cara melakukan himbauan-himbauan tentang K3 seperti pemakaian APD, melalui pemasangan poster-poster $\mathrm{K} 3$ atau dengan sistem reward and punishment (Tjakra, J., Sepang, B., dan Walangitan).

Pemeliharaan di unit sarana dibagi menjadi pemeliharaan harian dan pemeliharaan bulanan. Pemeliharaan bulanan dibagi menjadi pemeliharaan 1 bulan (P1), pemeliharaan 3 bulan (P3), pemeliharaan 6 bulan (P6) dan pemeliharaan 
12 bulan (P12). Pemeliharaan berupa pemeliharaan lokomotif dan kereta. Pemeliharaan harian dilakukan sebelum dan sesudah kereta beroperasi, sedangkan pemeliharaan bulanan dilakukan untuk menjaga kondisi lokomotif dan kereta selalu dalam keadaan optimal.

Dipo lokomotif dan dipo kereta Yogyakarta masing-masing memiliki tim P2K3. Sekretaris P2K3 baik dipo lokomotif maupun dipo kereta Yogyakarta bertanggungjawab membentuk tim inspeksi yang terdiri dari ketua, sekretaris dan anggota inpesksi. Tim inspeksi melakukan tugasnya dan melaporkan hasil kegiatan inspeksi, kemudian menindaklanjuti hasil inspeksi. Inspeksi berupa observasi cara kerja, perilaku pekerja, peralatan, sarana K3 dan kondisi lingkungan kerja. Hasil inspeksi dipublikasikan kepada seluruh karyawan dan hasil inspeksi dapat diakses oleh semua karyawan. Inspeksi merupakan suatu program pencegahan yang sangat penting yang dapat dilakukan untuk menjamin lingkungan kerja selalu aman, sehat dan selamat (Pratomo, A. dan Widajati. N).

Tim P2K3 bertanggung jawab terhadap terlakasananya suatu investigasi di lokasi kerja. Dalam keadaan darurat di lokasi kerja diantaranya bencana alam, kebakaran, ancaman bom, banjir dan sebagainya unit sarana memiliki instruksi kerja termasuk tindakan pencegahan seperti pengadaan Alat Pemadam Api Ringan (APAR) di tempat kerja.

Unit sarana memiliki potensi terjadinya kecelakaan dan penyakit akibat kerja. Setiap terjadi insiden, kecelakaan dan penyakit akibat kerja di unit sarana terdapat prosedur pelaporan dan penyelidikannya. Semua pekerja unit sarana wajib melaporkan kepada atasannya apabila melihat atau mengalami suatu insiden, kecelakaan atau penyakit akibat kerja. Pelaporan dilakukan kepada atasannya berupa laporan lisan terlebih dahulu kemudian laporan secara tertulis.

Keselamatan dan kesehatan kerja menjadi kewajiban semua pihak sehingga semua wajib berperan aktif walaupun dalam porsi yang berbeda-beda sesuai level jabatannya. Budaya K3 bukan sebatas menjadi wacana tetapi harus menjadi tanggung jawab bersama tidak hanya pimpinan atau Tim K3 (Salafudin, M., Ananta, H., dan Subiyanto).

\subsubsection{Pemahaman dan Kepatuhan Pekerja Unit Sarana Terhadap SOP K3}

Pemahaman dan kepatuhan yaitu perilaku seseorang dalam memberikan tanggapan terhadap peraturan atau ketetapan yang ada dalam sebuah perusahaan. Pemahaman adalah bagaimana seseorang mengetahui, mengerti, dapat membedakan dan dapat menerangkan peraturan yang berlaku. Kepatuhan adalah sikap kesediaan dan kerelaan seseorang untuk mematuhi dan menaati norma-norma peraturan yang berlaku disekitarnya.

Pekerja unit sarana secara keseluruhan memiliki pemahaman yang baik terhadap SOP K3, hal ini dibuktikan bahwa pekerja unit sarana mampu menjelaskan, membedakan dan menerangkan SOP K3 yang ada di unit sarana. Para pekerja unit sarana mampu menjelaskan dan menerangkan tentang alat pelindung diri, prosedur keadaan darurat, perawatan, mampu membedakan dan menerangkan arti dari setiap rambu-rambu K3 yang ada di unit sarana, selain itu para pekerja unit sarana juga sadar dan mengerti potensi bahaya yang ada di unit sarana.

Pemahaman pekerja unit sarana terhadap SOP K3 sudah cukup baik, akan tetapi kepatuhan pekerja unit sarana terhadap SOP K3 perlu ditingkatkan. Hal ini dapat dibuktikan dengan masih terdapat beberapa pekerja yang merokok di tempat kerja, tidak memakai APD saat di tempat kerja, dan tidak melaporkan atau mencatat jika terjadi kecelakaan di tempat kerja seperti tergores, terjepit, tersayat, terpecik api dan sebagainya. Hal ini diperkuat dengan tidak adanya data atau laporan kecelakaan akibat kerja di unit sarana. Hanya kecelakaan kerja yang berdampak fatal seperti terjatuh dari ketinggian yang menyebabkan patah tulang yang dilaporkan dan dilakukan pencatatan. 
Kepatuhan terhadap suatu peraturan yang diterapkan di lingkungan pekerjaan merupakan kehendak dan kesediaan pekerja untuk memenuhi dan mentaati segala prosedur dan ketentuan-ketentuan yang berlaku, baik secara tertulis maupun tidak tertulis. Kepatuhan pekerja tidak akan terbentuk dengan sendirinya tanpa disertai dengan upaya yang dilakukan oleh pimpinan (Hasan, I. 2015).

\subsubsection{Kesesuaian SOP K3}

Kesesuaian SOP K3 yaitu kecocokan atau keselarasan antara penerapan SOP K3 di unit sarana dengan SOP K3 yang sudah ditetapkan oleh unit sarana PT Kereta Api (Persero) Daerah Operasi VI Yogyakarta. Unit sarana memiliki 6 SOP K3 utama yang wajib untuk dipahami dan dilaksanakan oleh setiap pekerja unit sarana. 6 SOP K3 tersebut diantaranya adalah Alat Pelindung Diri (APD); Inspeksi Kerja; Rambu-Rambu K3; Pelaporan dan Penyelidikan Insiden, Kecelakaan dan Penyakit Akibat Kerja; Pemeliharaan dan Keadaan Darurat.

Penerapan SOP K3 di unit sarana PT Kereta Api Indonesia (Persero) Daerah Operasi VI Yogyakarta sebagian besar telah sesuai dengan SOP K3 yang sudah ditetapkan oleh unit sarana PT Kereta Api Indonesia (Persero) Daerah Operasi VI Yogyakarta, akan tetapi ada beberapa hal yang perlu dibenahi dan dilengkapi.

Pemeliharaan yang ada di unit sarana sudah sesuai dengan ketentuan yang ditetapkan oleh unit sarana, dimana pemeliharan harian maupun bulanan terlaksana dengan sangat baik. Ramburambu K3 yang ada diunit saran sudah memenuhi dan sesuai dengan ketentuan yang ditetapkan yang meliputi penempatan, jumlah, bentuk, warna serta pemasangan. Inspeksi kerja diunit sarana juga sudah sesuai dengan ketentuan yang ditetapkan oleh unit sarana, dibuktikan dengan inspeksi dilakukan sebulan sekali, hasil inspeksi yang ditemukan ditempat kerja dipublikasikan dan dapat diakses seluruh pekerja unit sarana, hasil inspeksi kemudian ditindaklanjuti dan dilakukan perbaikan segera. Setiap keadaan darurat di unit sarana memiliki prosedur dan sudah sesuai dengan ketentuan yang ditetapkan oleh unit sarana, hal ini dibuktikan dengan salah satu prosedurnya yaitu tentang pengadaan APAR yang sudah sesuai dengan ketentuan.

Penerapan SOP K3 yang ada di unit sarana hampir seluruhnya sudah sesuai dengan SOP K3 yang ditetapkan oleh unit sarana. Hanya ada beberapa SOP K3 yang belum sesuai dengan SOP K3 yang ditetapkan oleh unit sarana seperti APD dan Pelaporan dan Penyelidikan Insiden, Kecelakaan dan Penyakit Akibat Kerja.

Pengadaan APD di unit sarana perlu ditingkatkan. Terdapat beberapa pekerja baru unit sarana yang belum mendapatkan APD, beberapa APD yang sudah harus diganti dan perawatan terhadap APD yang kurang. Pengurus wajib menyediakan APD bagi pekerja di tempat kerja, APD diberikan oleh pengurus secara cuma - cuma sesuai Keputusan Direksi PT Kereta Api Indonesia (Persero) No. KEP.U/LL.507/VI/1/KA-2012 tentang Alat Pelindung Diri di Lingkungan Kerja PT Kereta Api Indonesia (Persero). Pekerja unit sarana mengajukan APD sesuai dengan kebutuhan pekerjaannya kepada para pengurus, kemudian pengurus menindak lanjuti dengan memberi APD sesuai yang dibutuhkan oleh pekerja, tetapi pada kenyataannya pengadaan APD di unit sarana dinilai telat.

Pelaporan dan Penyelidikan Insiden, Kecelakaan dan Penyakit Akibat Kerja di unit sarana juga perlu ditingkatkan. Sesuai dengan prosedur yang dikeluarkan PT Kereta Api Indonesia (Persero) jika terjadi insiden, kecelakaan atau penyakit akibat kerja yang terjadi ditempat kerja maka pekerja baik yang mengalami atau melihat insiden, kecelakaan atau penyakit akibat kerja wajib melaporkan secara lisan dan tertulis. Kenyataan di lapangan bahwa pekerja hanya melaporkan insiden, kecelakaan atau penyakit akibat kerja yang berat seperti terjatuh dari ketinggian sampai patah tulang, sedangkan untuk insiden, kecelakaan atau penyait akibat kerja ringan seperti tergores, tersayat, terpecik api, terjepit dan sebagainya 
pekerja tidak melaporkannya. Hal ini diperkuat dengan tidak adanya data atau laporan insiden, kecelakaan atau penyakit akibat kerja kecil atau sedang diunit sarana.

Keberhasilan suatu kebijakan di perusahaan merupakan tanggung jawab bersama antara perusahaan dan karyawan, dimana keberhasilan dari kebijakan ini sepenuhnya terletak pada keterlibatan dari semua karyawan dengan cara menjalankan kebiasaan kerja yang terbaik dalam bidang kualitas lingkungan, kesehatan, dan keselamatan kerja (Zulyanti, 2013).

\section{KESIMPULAN DAN SARAN}

\subsection{Kesimpulan}

Berdasarkan hasil penelitian yang di lakukan, maka penerapan Standar Operasional Prosedur (SOP) Keselamatan dan Kesehatan Kerja (K3) di Unit Sarana PT Kereta Api Indonesia (Persero) Daerah Operasi VI Yogyakarta dapat disimpulkan sebagai berikut :

1) Kebijakan SOP K3 di unit sarana terdiri dari 6 komponen utama yang terdiri dari: Alat Pelindung Diri (APD); Pelaporan dan Penyelidikan Insiden, Kecelakaan dan Penyakit Akibat Kerja; Inspeksi Kerja; Rambu-Rambu K3; Pemeliharaan dan Keadaan Darurat.

2) Pemahaman pekerja unit sarana terhadap SOP K3 sudah cukup baik, akan tetapi kepatuhan pekerja unit sarana terhadap SOP K3 perlu ditingkatkan.

3) Penerapan SOP K3 seperti Inspeksi Kerja; Rambu-Rambu K3; Pemeliharaan dan Keadaan Darurat sudah sesuai dengan SOP K3 yang sudah ditetapkan oleh unit sarana, sedangkan SOP K3 seperti Alat Pelindung Diri (APD); Pelaporan dan Penyelidikan Insiden, Kecelakaan dan Penyakit Akibat Kerja belum sesuai dengan SOP K3 yang sudah ditetapkan oleh unit sarana.

\subsection{Saran}

Berdasarkan hasil kesimpulan penerapan Standar Operasional Prosedur (SOP) Keselamatan dan Kesehatan Kerja (K3) di Unit Sarana PT Kereta Api Indonesia (Persero) Daerah Operasi VI Yogyakarta, maka saran yang diberikan adalah :

1) Bagi Manajemen Unit Sarana

a) Hendaknya membentuk tim khusus yang memantau kepatuhan pekerja terhadap SOP K3 seperti pemakaian APD, Pelaporan dan Penyelidikan Insiden, Kecelakaan dan Penyakit Akibat Kerja serta mencatat semua insiden, kecelakaan dan penyakit akibat kerja.

b) Memberikan sanksi yang tegas apabila terdapat pekerja yang melanggar atau tidak mematuhi SOP K3.

2) Bagi Pekerja Unit Sarana

a) Agar lebih meningkatkan lagi kepatuhan terhadap SOP K3 terutama pemakaian APD di tempat kerja dan Pelaporan dan Penyelidikan Insiden, Kecelakaan dan Penyakit Akibat Kerja.

b) Agar melaporkan dan mencatat jika terjadi insiden, kecelakaan dan penyakit akibat kerja sekecil apapun, tidak hanya insiden, kecelakaan dan penyakit akibat kerja yang berat saja yang dilaporkan dan dicatat. 


\section{DAFTAR PUSTAKA}

Hasan, I.. Analisis Kepatuhan Karyawan Bagian Produksi Pada Standar Operasional Prosedur (SOP) Keselamatan dan Kesehatan Kerja (K3) di PT Polytama Propindo Indramayu Jawa Barat, Skripsi, Fakultas Kesehatan Masyarakat, Universitas Ahmad Dahlan, Yogyakarta, 2015.

Kountur, R. Metode Penelitian Untuk Penulisan Skripsi dan Tesis. Penerbit PPM, Jakarta, Hal. 53, 2004.

Pratomo, A. dan Widajati. N. Tingkat Pemenuhan Safety Inspection Menurut International Safety Rating System di Bukit Tua, The Indonesian Journal of Occupational Safety and Health, Vol. 2, No. 1, Hal.28-33, 2013.

PT Kereta Api Indonesia. Company Profile, Bandung, Hal. 2, 4-5, 2014.

Salafudin, M., Ananta, H., dan Subiyanto. Implementasi Sistem Manajemen Keselamatan dan Kesehatan Kerja di PT PLN (Persero) Area Pengatur Distribusi Jawa Tengah \& D.I. Yogyakarta dalam Upaya Peningkatan Mutu dan Produktivitas Kerja Karyawan, Jurnal Teknik Elektro, Vol. 5, No. 1, Hal. 26-31, 2013.

Suci, R., Restuatuti, T., Fatmawati. Hubungan Pengetahuan dan Sikap Petugas Laboratorium Patologi Klinik Terhadap Penerapan Standard Operating Procedure (SOP) Penanganan Bahan Infeksius di RSUD Arifin Achmad Provinsi Riau, Jom Fakultas Kedokteran, Vol. 1, No. 2, Hal. 1-11, 2012.

Tjakra, J., Sepang, B., dan Walangitan.. Manajemen Risiko K3 pada Proyek Pembangunan Ruko Orlens Fashion Manado, Jurnal Sipil Statik, Vol. 1, No. 4, Hal. 282-288, 2013.
Zulyanti, Komitmen Kebijakan Keselamatan dan Kesehatan Kerja (K3) Sebagai Upaya Perlindungan Terhadap tenaga Kerja (Studi pada Mitra Produksi Sigaret KUD Tani Mulyo Lamongan), Jurnal Administrasi Publik, Vol. 11, No. 2, Hal. 264 - 275, 2013.

\section{Lampiran Pertanyaan Untuk Responden}

\section{A. Kebijakan SOP K3}

1. Apakah ada Standar Operasional Prosedur (SOP) Keselamatan dan Kesehatan Kerja (K3) di unit sarana?

2. Ada berapa SOP K3 di unit sarana?

3. Seperti apa SOP K3 yang ada di unit sarana?

B. Kepatuhan SOP K3

1. Apakah unit sarana mewajibkan setiap pekerja untuk mamatuhi dan melaksanakan SOP K3 saat bekerja?

2. Apakah unit sarana memberikan instruksi dan penjelasan kepada pekerja tentang SOP K3?

3. Apakah ada team khusus yang memantau kepatuhan pekerja unit sarana terhadap SOP K3?

4. Apakah ada sanksi terhadap pekerja yang tidak mematuhi SOP K3 dalam bekerja?

C. Pemahaman SOP K3

1. APD

a. APD apa saja yang terdapat di unit sarana?

b. Apakah anda selalu memakai APD saat bekerja?

c. Apakah anda mengetahui fungsi dari setiap APD tersebut?

2. Pelaporan dan Penyelidikan Insiden, Kecelakaan dan Penyakit Akibat Kerja

a. Bagaimana prosedur pelaporan insiden, kecelakaan atau penyakit akibat kerja di unit sarana? 


\section{Inspeksi Kerja}

a. Bagaimana inspeksi kerja di unit sarana?

b. Siapa yang melakukan inpseksi kerja di unit sarana?

\section{Rambu-Rambu K3}

a. Seperti apa rambu-rambu K3 yang ada di unit sarana?

b. Apakah anda mengerti maksud dari rambu-rambu K3 yang ada di unit sarana?

\section{Pemeliharaan}

Bagaimana prosedur melakukan pemeriksaan dan pemeliharaan sarana dan peralatan di unit sarana?

6. Keadaan Darura

Bagaimana prosedur keadaan darurat yang ada di unit sarana? 